\title{
FINANCIAL LIFE AFTER LIBOR
}

Levente Kovács - Ildikó Kajtor-Wieland - Péter Vass ${ }^{1}$

\begin{abstract}
The introduction of the study outlines the need for a reference interest rate and introduces one of its most well-known type, the LIBOR (London Interbank Offered Rate) as well as attempts to manipulate it. After this, the paper assesses and provides an overview of the regulatory attempts aimed at reforming the index. In addition, the European and global regulatory environment is also discussed, as well as the tasks to be completed prior to regulation. Finally, recommendations are provided on the Hungarian reference interest rate framework and the establishment of a dedicated working group is also suggested.
\end{abstract}

JEL codes: $\mathrm{E}_{43}, \mathrm{G} 21, \mathrm{G} 28$

Keywords: reference interest rate, LIBOR, manipulation, reform

\section{THE NEED FOR AND THE FEATURES OF A REFERENCE INTEREST RATE}

The existence of a generally accepted reference interest rate is one of the practical bases for the operation of the financial sector. In order to calculate the price of financial products, such as e.g. the interest of SWAP, loan and deposit transactions, as well as that of treasury products, it is usually important to know the current and accurate value of the reference interest rate. According to Schrimpf (2019), in addition to this need, the main functional requirements related to the reference interest rate are the followings:

1 Levente Kovács, secretary general, Hungarian Banking Association; professor, University of Miskolc. E-mail: kovacs.levente@bankszovetseg.hu.

Ildikó Kajtor-Wieland, director, Hungarian Banking Association. E-mail: kajtor-wieland. ildiko@bankszovetseg.hu.

Péter Vass, deputy secretary general, Hungarian Banking Association. E-mail: vass.peter@ bankszovetseg.hu. 
i. Robust and accurate representation of interest rates in core money markets (not susceptible to manipulation);

ii. Reference rate for financial contracts (beyond money markets). Usable for discounting / pricing cash instruments \& IR derivatives;

iii. Benchmark for term lending and funding. Financial intermediaries act both as lenders and borrowers. Require ending benchmark having not too differently from the rates at which they raise funding.

In the financial markets, based on general agreement, the LIBOR (London Interbank Offered Rate) set by the British Bankers' Association, as a reference interest rate quoted by the most important banks in London, the leading international financial centre of the world, has been widely used since 1986 . LIBOR became more conspicuous in the 1980s, as interbank trading transactions were getting more widespread. Since then, its application has become more general in loan relationships between banks and clients (Pásztor, 2018). Confidence in London as a global financial centre strengthened the openness of all financial institutions, corporate and retail actors to the acceptance of LIBOR-based transactions.

Over the last few decades, the functional requirements described above have been fulfilled by the traditional quotation methodology below. The British Bankers' Association produced a dedicated BBA LIBOR website (no longer available) which explained the system and listed those banks which made up the contributor panels for each currency calculated, including the panel for the Sterling LIBOR rate. The data was collected by a company on behalf of the BBA and underwent a fixing process before the LIBOR rate was released each business day. The individual contributor rates from each bank that made up the panel were not freely available through the website but could be found through some subscription-based services such as Bloomberg (ICAEW, 2021). Due to scandals presented later, administrative tasks related to LIBOR were delegated to CE Benchmark Administration Ltd. in 2014 .

Only major banks with some activities in London in the case of which short-term borrowing carried practically minimal (zero) risk were allowed to take part in the price-setting of LIBOR. On the one hand, such LIBOR-quoting banks were wellknown, on the other hand, they had excellent business reputation. Panel banks provide potential loan and deposit offers on every business day. The difference between interests on loan and deposits is traditionally one-eight, i.e. $0.125 \%$, which has decrease due to the low level of interest rates recently. In the light of the above, owing to short maturity and the rating of participants, the quotes were considered to be prices exclusive of risk premium.

Regarding quotations, liability may be increased by trading volume obligation, which is common practice in the case of other kind of IBOR (Interbank Offered 
Rate) pricing, however, it is also subject to constant debate. The minimum amount that is high enough for panel banks to quote real market levels, thus reducing the possibility of arbitration is still unknown. On the other hand, the extent of the expected counterparty risk limit that all panel banks have to take on in such cases within each maturity towards other banks involved in the quotation on a daily basis is also important. Of course, taking part in price quotation is worth not only for prestige, as market prices follow the current situation of individual banks in this way. When calculating LIBOR (like the London Interbank Bid Rate, LIBID), the administrator has to filter out the $25 \%$ highest and $25 \%$ lowest prices, then has to calculate LIBOR itself, the value of the average price rounded to two decimal places based on the remaining 50\%. Annually, min. eight, but max. sixteen panels banks are selected to conduct loan and deposit interest quotations for each quoted foreign exchange (GBP, USD, JPY, EUR, CHF) and all specified maturities (overnight, one week, two, three, six and twelve weeks) possibly on each business day (Global Rates, 2021). This may mean max. 35 loan (LIBOR) and max. 35 deposit (LIBID) quotations.

Panel banks act circumspectly and with a great deal of responsibility. They try to bid prices that are supported by the quoted prices in the market. Due to circumspection, if there is no significant change in the market, consecutive days tend to fit together well. Accordingly, the LIBOR curve drawn on the basis of classic quotation methodology is typically a curve suggesting "tranquillity" and moving with low amplitude within short terms. By calculating LIBID, quotation methodology enabled the pricing of deposit, investment products, however, it has not become widespread. At the same time, LIBOR has become the primary loan reference interest rate for all the six main currencies, with short maturities, in financial markets over the past few decades, slightly overlapping the prime rate period.

\section{THE MANIPULATION OF LIBOR}

The manipulation of LIBOR revealed in 2012 fundamentally rocked confidence in the financial sector and drew the regulators' attention to the eventuality of interest rate quotation practices (Fliszár, 2015) and their operation without being based on real market transactions (Kinger-Syrstad, 2021; Duffie-Stein, 2015; Schrimpf-Suschko, 2019; Stenfors-Lindo, 2018). The annual report for the year 2010 published by the Swiss UBS bank on 15 March 2011 drew the market's attention to possible manipulation by the bank, mentioning that American authorities (SEC, US Commodity Futures Trading Commission and the US Department of Justice) summoned UBS to a hearing for the bank's possible involvement in the LIBOR's manipulation (UBS Annual Report, 2021:55). At the time, the authorities 
were already investigating the unusual and suspicious movement of LIBOR and were trying to find out its reason.

Since 2003, the amount of loan related to LIBOR quotations has been USD 300 thousand billion. After the investigation, the United States, the United Kingdom and the European Union imposed a fine of USD 9 billion on 15 institutions conducting the quotation of the reference rate, including Barcalays, the Royal Bank of Scotland, Rabobank and UBS (CFR, 2016).

In order to expose the scandal, it is worth highlighting the operating elements of the LIBOR reference rate which enabled its manipulation and explain why the otherwise profit-oriented financial institutions manipulated it. In the light of the above, at the end of our study, when predicting future prospects, not only the termination/phasing-out of LIBOR will be important, but also all the conclusions drawn in connection with its operation so far, which could allow the switch to and the application of a more efficient benchmark having regard to the events described above.

As it was explained earlier, LIBOR is a benchmark interest rate that aims to show the average interest rate at which institutions provide loan to each other, and, inter alia, both corporate and retail financial contracts comply with it in terms of floating rates (Youle, 2014). The quotation of LIBOR is not an interest rate calculated on the basis of the interests of actually realised loans, but rather the average of expectedly assumed/offered by the institutions involved in its quotation, projected to different currencies and terms (Guardian, 2017). In order to illustrate why manipulation could have occurred, we explore possible reasons from two perspectives, by means of the following examples:

The interest rate swap may oblige one of the parties to exchange the LIBOR (variable cash flow) of USD 1 million for the 8\% fixed interest rate of USD 1 million. In this way, the cash flow the two parties swap corresponds to the $8 \%$ interest rate of a fixed-interest bond and the LIBOR of a bond with variable interest rates. The swap deal facilitates for the participants the reorganisation of their balance sheets (Bodie-Kane, 2014:913-914). Referring to the example, the interest rate swap is a much cheaper and faster way of restructuring cash flows related to the balance sheet, as when issuing bonds or borrowing, it enables the realisation of the cheapest form due to price advantage, and then converts it to the financing method that is the most appropriate to the participant's business needs. Accordingly, it will be accounted as one of the banks' fixed interest rate minus the LIBOR rate. In order to maximise cash flow, the bank has to keep the reported interest rate below the real level, and, of course, depending on its position, it might be true upwards, as well.

Secondly, despite the fact that the individual LIBOR quotes were public, and thus public control existed, the banks were interested in keeping the interest rate con- 
tinuously low, as this situation put pressure on the institutions (often by the management) to submit a publicly available quote that does not reflect the pricing of real loans. Conclusions might have been drawn concerning the liquidity situation of the given bank (Strotkamp, 2018).

Based on the two cases above, along with the phasing-out of LIBOR, it might be worth drawing those conclusions which draw our attention to the lessons. The LIBOR scandal showed the vulnerability of the financial market, which affects not only the appropriate methodology (the lack of the four eyes principle, checks and balances), but also dependency on a certain interest rate and concentration. The market and the regulators have paid and will pay special attention to this. Eventually, in the framework of a multiannual reform, reference interest rates were regulated, a comprehensive review of transparency and the methodology was conducted (Erhart et al., 2013:2).

\section{LIFE AFTER LIBOR}

\subsection{Introduction and the reasons for change}

A properly working reference rate is indispensable for the effective operation of the financial system, as such rates are substantial cornerstones of contracts in the financial market. Moreover, they may also play a role in the transmission mechanism of central banks (ECB, 2017). Recently, intense reform of reference rates has started, based primarily on the lessons learnt from LIBOR manipulation, the results of the crisis and market needs.

One of the reasons for LIBOR's termination was that the English Financial Conduct Authority and, ultimately, the market was concerned that LIBOR was an index that was not sustainable any longer, in spite of the fact that the reforms, the quotation of the reference rate calculation based increasingly on real transactions and the adoption of a powerful control mechanism were on the horizon. The volume of trading decreased, the confidence of market participants in the index weakened. In the end, in 2017, after consultation and agreement with larger banks, the English Financial Conduct Authority announced the deadline of LIBOR's phasing-out (the end of 2021 - UK Finance, 2019:4-5).

With regard to the fact that being connected to LIBOR affected several financial institutions and a wide range of their contracts, collective and coordinated preparation that enabled smooth transition in legal and economic sense and ensured the uninterrupted operation of the market was required on the part of the regulators, authorities, the central bank and the market. 
In the European Union (and in Hungary), the legislative environment concerning reference yields has multiple levels. Its structure consists of a directly effective Regulation (EU), its implementing Regulation (EC) and, e.g. in the case of EURIBOR, the Governance Framework required by the given reference yield's administrator, the European Money Markets Institute (hereinafter referred to as EMMI), which operates under the aegis of the European Banking Federation ${ }^{2}$ (EMMI, 2019). Consequently, the regulatory hierarchy and content described above also apply to the reference yields which are to replace the terminating LIBOR. In view of the above, in the case of reference yields selected by financial institutions, full compliance with the regulation shall be a basic condition in the future. Any further actions in the process of transformation shall be taken based on business and legal consideration, in accordance with this condition. It is a very complex process, as the appropriate selection of reference rates is of critical importance with regard to the operation of the bank and the balance sheet, in particular to the cost of financing and the repricing of contracts.

After the regulatory revision following the LIBOR scandal and the announcement of LIBOR's phasing-out, in several regions of the world, there was a need to establish working groups to set new/existing reference rates and clarify the legal questions of the exchange process. LIBOR was manipulated not only for reasons of "profit-making" or position improvement, but also because such an interbank interest rate has several inherent risks (risks which exist even without manipulation). For example, such risks include the following: On the one hand, interbank interest rates are not risk-free, as they also carry a bank risk factor, whose full calculation, ab ovo, requires subjective expert estimate. On the other hand, the index would show the pricing of unsecured loans, which have represented a less typical transaction type since the crisis of 2008. Recognising the limits of the existing indicators and the fall in their quotation, regulatory authorities attempted to reform the system of earlier reference rates first (the so-called IBOR+ system). As the volume of transactions did not increase significantly, they decided to introduce new reference rates, the so-called Alternative Reference Rates (ARRs) (KPMG, 2019:2).

2 Regulation (EU) 2016/1011 of the European Parliament and of the Council of 8 June 2016 on indices used as benchmarks in financial instruments and financial contracts or to measure the performance of investments funds and amending Directives 2008/48/EC and 2014/17/EU and Regulation (EU) No 596/2014.

- Commission Delegated Regulation (EU) 2018/1637-1646 of 13 July 2018 supplementing Regulation (EU) 2016/1011 of the European Parliament and of the Council

- The Governance Code of Conduct sets out the governance arrangements and control framework established by EMMI, in its role as administrator of EURIBOR, for the provision of the benchmark 


\subsection{Possible future reference yields in financial markets}

In the case of each currency, LIBOR is swapped for an interest rate corresponding to the specific currency and tenor. However, it is important to emphasise that conversion is not compulsory for institutions, it is only an opportunity. They have to right to apply a different reference rate, as well. Currently, LIBOR is quoted in five $^{3}$ currencies (USD, EUR, GBP, JPY and CHF) and seven tenors in the case of each currency (ICE, 2021).

Several years ago, the EMMI started the revision of the EURIBOR methodology, taking into account the prevention of any possible manipulation in the future. Based on Vainikainen (2018), the following table summarises the individual reference rates for the currency EUR.

Table 1

Reference rates affecting the euro

\begin{tabular}{|c|c|c|c|c|}
\hline & EONIA & ESTER & EURIBOR & Reformed EURIBOR \\
\hline Status & $\begin{array}{l}\text { It is to be } \\
\text { terminated, as it } \\
\text { fails to comply } \\
\text { with the Bench- } \\
\text { mark regulation. }\end{array}$ & $\begin{array}{l}\text { It has been } \\
\text { published by the } \\
\text { European Central } \\
\text { Bank since } 2019 . \\
\text { The administrator } \\
\text { is the European } \\
\text { Central Bank. }\end{array}$ & $\begin{array}{l}\text { Its method does not } \\
\text { comply with the } \\
\text { BMR (Benchmark } \\
\text { regulation). The } \\
\text { administrator is the } \\
\text { EMMI. }\end{array}$ & $\begin{array}{c}\text { The new EURIBOR } \\
\text { (hybrid) received } \\
\text { the authorization } \\
\text { in accordance with } \\
\text { BMR from the } \\
\text { Belgian authority on } \\
2 \text { June } 2019 .\end{array}$ \\
\hline $\begin{array}{l}\text { Tenor } \\
\mathrm{W}=\text { Week } \\
\mathrm{M}=\text { month }\end{array}$ & $\mathrm{O} / \mathrm{N}$ & $\mathrm{O} / \mathrm{N}$ & $\begin{array}{c}1 \mathrm{~W}, 2 \mathrm{~W}, 1 \mathrm{M}, 2 \mathrm{M}, 3 \mathrm{M} \\
6 \mathrm{M}, 9 \mathrm{M}, 12 \mathrm{M}\end{array}$ & $1 \mathrm{~W}, 3 \mathrm{M}, 6 \mathrm{M}, 12 \mathrm{M}$ \\
\hline $\begin{array}{l}\text { Transaction } \\
\text { price or } \\
\text { asking price }\end{array}$ & Transaction-based & Transaction-based & $\begin{array}{l}\text { based on the } \\
\text { asking prices of the } \\
\text { participating banks }\end{array}$ & $\begin{array}{c}\text { hybrid, } \\
\text { fundamentally } \\
\text { transaction-based, } \\
\text { failing this, other } \\
\text { pricing methods }\end{array}$ \\
\hline Description & $\begin{array}{l}\text { The weighted } \\
\text { average price } \\
\text { of unsecured } \\
\text { overnight loans } \\
\text { in the interbank } \\
\text { market (EU) }\end{array}$ & $\begin{array}{l}\text { The current } \\
\text { transaction fee } \\
\text { of specific loans, } \\
\text { reported by the } \\
\text { credit institutions } \\
\text { based on the ECB's } \\
\text { MMSR (Money } \\
\text { Market Statistical } \\
\text { Reporting) }\end{array}$ & & $\begin{array}{l}\text { The interest rate of } \\
\text { loan transactions } \\
\text { of higher amount } \\
\text { between credit } \\
\text { institutions (EU) }\end{array}$ \\
\hline
\end{tabular}

Source: own editing based on Vainikainen (2018:2), EMMI (2018) and ECB

3 Earlier, more specifically until 2013, there were AUD, CAD, NZD, SEK, DKK LIBOR rates, as well. 
On 2 June 2019, the EMMI received the administrator license from the Belgian Financial Services and Markets Authority (BFSMA) in accordance with Article 34 of the BMR regarding EURIBOR. Consequently, financial institutions have had the right to use the new EURIBOR in the case of new contracts/instruments since 1 January 2020. EURIBOR is considered to be a critical benchmark based on the BMR (EMMI, 2021). The EMMI is responsible for the integrity and reliability of EURIBOR.

The so-called Governance Framework document contains the regulation of EURIBOR. The regulatory structure is illustrated in the following figure:

\section{Figure 1}

\section{EMMI's regulation of EURIBOR}

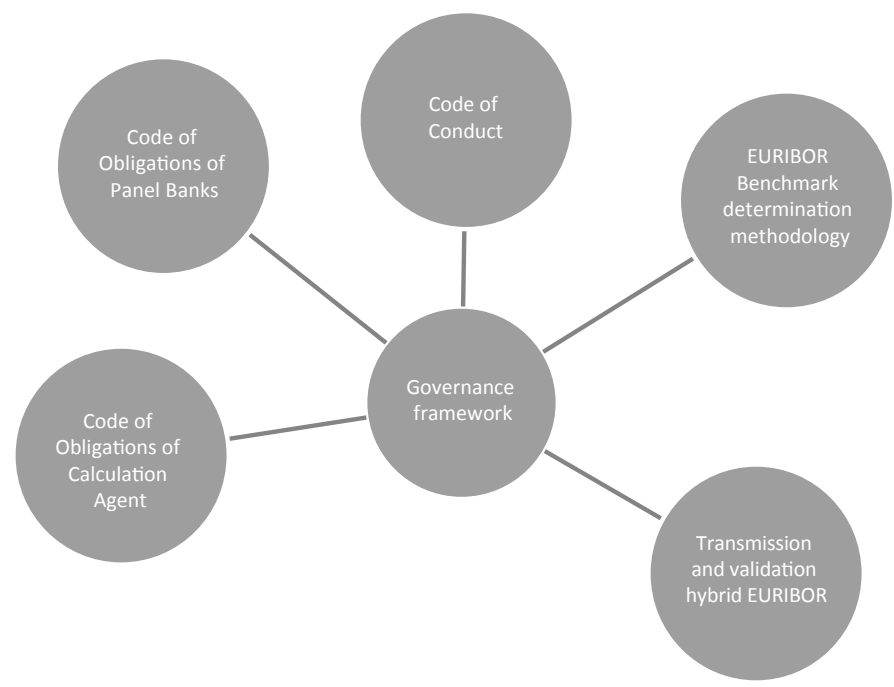

Source: own editing based on EMMI (2021)

EURIBOR is set by the active participants (credit institutions) of the euro market, the so-called panel banks, whose composition is suitable for setting the average value in a diversified manner. The suitability of the panel banks for this role is examined by the so-called Steering Committee of the EMMI, which also sets the criteria for the panel banks' entry (EMMI, 2019).

Based on the Benchmark Determination Methodology, EURIBOR aims to reflect the underlying interest rate of EUR money market transactions, which is transaction-based, but is complemented by a three-stage hierarchical system. The first stage includes only the interest rate of the underlying product over the matu- 
rity period, in accordance with the formula provided by the EMMI. The second stage contains the entire maturity spectrum of the money market, while the third phase also includes the transactions of those participants who are closely related to the euro money market but cannot be classified in the transaction data levels above. At this stage, modelling technique and the expert estimate of panel banks appear. The stages follow each other in consecutive order.

EURIBOR is published by the EMMI through the agent who conducts the calculation, with a 24-hour delay after the arrival of the data. Following the daily calculation, real-time reference yields are available to the authorised traders of EMMI already before the publication

It is clear that despite not being a new reference rate index, EURIBOR has been considerably and positively developed in order to ensure its compliance with the EU Regulation and the restoration of market confidence. By transition and conversion, we mainly mean the conversion to new EURIBOR owing to the termination of LIBOR. However, it is worth mentioning that previous EURIBOR-based transactions have to be reviewed by the institutions.

\subsection{Aspects to consider for the future}

Basically, transition from the LIBOR reference yield should be examined from two aspects, which are obviously closely related, on the one hand, regarding the funding costs of interbank interest rates, on the asset side, in terms of loan agreements provided by the bank to non-banks.

In the case of costs of funds, when the contracting parties are two financial institutions, in order to facilitate the transition, the International Swaps and Derivatives Association (hereinafter referred to as ISDA) prepared a so-called Fallback Protocol document (ISDA, 2020), which is a basic guideline for OTC derivatives regarding the conversion of the terminating reference yield. In OTC transactions, the protocol is compulsory for those who have adopted it. Specific procedures apply to regulated markets or trading venues (including derivatives) if the two participating parties have signed the ISDA protocol. Incidentally, the ISDA (2020:36) specifies those cases and related actions when a reference yield ceases to exist, e.g. by announcement or if its cessation is published in any other way (Index Cessation Event). If the parties applying the benchmark are parties of the ISDA Master Agreement agree to be bound by the agreement, instead of the terminating reference yield, a pre-set reference yield shall apply to OTC derivatives pursuant to the Fallback Protocol, as of the dates laid down in advance (ISDA, 2020:34). As far as other, non-OTC transactions are concerned, the content of the practice is the same as that of the ISDA Protocol. 
In connection with the ISDA Fallback Protocol, financial consultancy firm PWC declared the following (PWC, 2020): "The ISDA fallback protocol (and its supplement) is only intended to be a backup plan. Some describe the protocol as a seatbelt: it can prevent serious injuries in case of a crash, but it's much wiser to avoid the crash in the first place."

Presumably, the ISDA protocol provides a solution to the transition between market participants related to derivatives, however, regarding other costs of funds, financial institutions should have individual negotiations, which entails an incalculably high number of working hours and unpredictably high costs. Of course, despite the fact above, the parties have the right to consider the ISDA protocol to be applicable to the settlement of other, non-(OTC) derivative transactions, as well. The European Central Bank (ECB), other authorities and working groups try to urge market participants in terms of transition to some specific benchmarks from the existing LIBOR-based settlement, at the level of regional (country, euro area) indices or currency and terminus/tenor-specific indices.

Related to the transition, in addition to costs of funds, the asset side of the balance sheets of credit institutions should be mentioned, as well, in terms of loans with floating rates provided to non-financial institutions, e.g. consumer mortgage loan contracts, where compliance with other laws shall be ensured and there is narrow room for manoeuvre regarding costs enforceable from the consumer and other rights. The rate of fixed-interest mortgage loans and mortgage loans with floating rates varies from country to country. As a result, the modification of the reference rate might have various effects (on consumer rights, indirectly on real property prices, etc.) (Kovács-Pásztor, 2018). The modification shall be in compliance with EU's consumer protection rules, as well as other provisions of civil and contract law which affect the entry into the contract and the inclusion of the given reference rate. 


\section{Figure 2}

\section{The percentage of gross mortgages of variable interest rates}

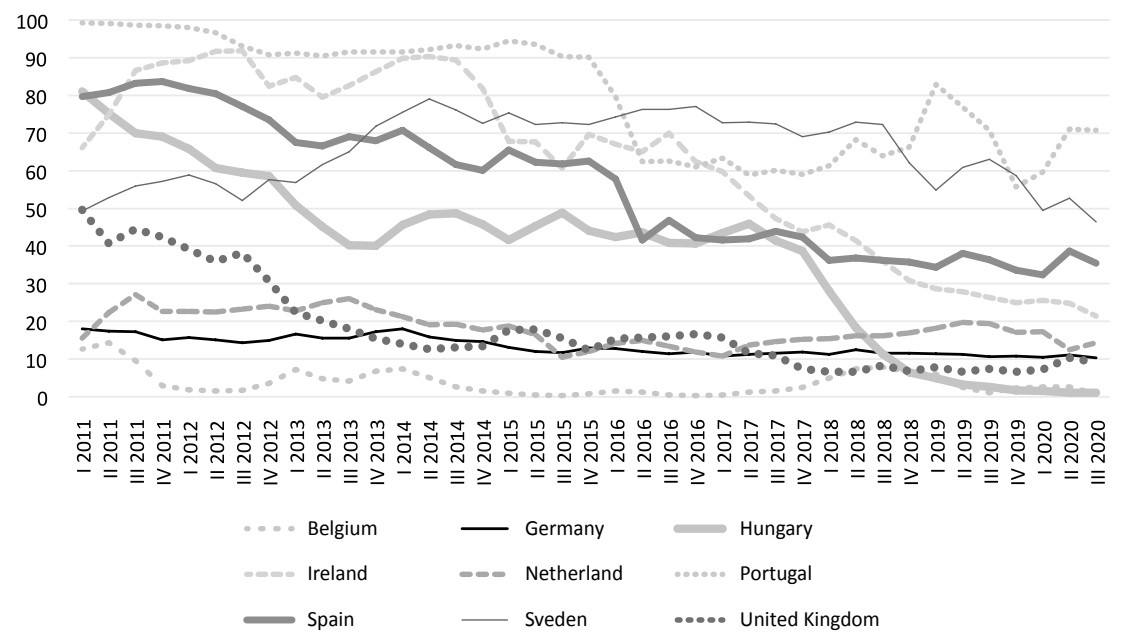

Source: https://hypo.org/ecbc/publications/quarterly-reviews/

Finally, we should mention that the ECB examined preparedness for the transition to new reference yields in the case of credit institutions, in the framework of a large-scale project in 2019. Based on this survey, the ECB found that credit institutions primarily focused on overnight reference yields (on ESTER instead of EONIA), rather than on the long-term EURIBOR. In the light of the survey, the ECB published a report $(E K B, 2020)$, which, based on the conclusions drawn, helps the banks in operating their management structure, risk management and transition to more effective action plans and documentation which are in accordance with good practice.

This part of the study reveals that despite the fact that the work processes related to the transition and the preparation started several years ago, conversion to reference yields will impose further duties on financial institutions. Transition might bring about significant changes on the side of assets as well as that of liabilities and covers a wide spectrum of risks in terms of business, operating loan and other (taxation, accounting) aspects. However, the benefit of reference yield conversion is incontestable. As a result of lessons learnt from mistakes, a reference rate that meets market demand and confidence is set. This reference rate is a new financial evolutionary milestone, as well. It is observable that global efforts set the main trends regarding reference rate conversion, however, accordingly, individual active compliance and implementation are necessary and inevitable on the 
part of financial institutions. The next part of the study provides a global outlook, while further detailing the process of the reform of benchmarks.

\section{THE PROCESS OF THE REFORM OF BENCHMARKS IN A GLOBAL PERSPECTIVE}

Following the LIBOR scandal discussed earlier and based on the still unproven suspicion related to further globally used IBORs (Interbank Offered Rates) to maintain confidence, which was fragile due to the financial crisis anyway, in the financial system, in addition to the existing regulators, large global and supranational regulators also reacted to the phenomenon immediately. In September 2012, the IOSCO (International Organization of Securities Commissions) set up its high-level action group run by the Americans and the British, which issued its material laying down the basic principles for reliable and independent financial benchmarks in July 2013, following more than half a year of market consultation (IOSCO, 2013). Also in September, the European Commission started a market consultation on a possible regulatory framework of benchmarks, which would have prescribed their creation and use, as well. The ESMA (European Securities and Markets Authority) and the EBA (European Banking Authority) published the basic principles applicable to the European Union somewhat earlier than the IOSCO (ESMA-EBA, 2013). The BIS (Bank for International Settlement) also examined the central bank-related aspects of this issue in its study published in March 2013.

It is apparent that the organisations made their proposals concurrently in the beginning, therefore the FSB (Financial Stability Board) set up a committee consisting of prominents of central banks and regulatory authorities (Official Sector Steering Group, OSSG) in July 2013 to coordinate the regulatory address of the problem at global level. Eventually, the international management of the issue was discussed at the G20 Summit in Saint Petersburg in September 2013, where the IOSCO principles and the control over global coordination by the FSB were approved. ${ }^{4}$

As a global control authority, the FSB drafted its recommendations (FSB, 2014) on the most important reference interest rates for regulators and financial authorities in June 2014. The tasks to be completed in the course of the reform process were listed under the following main points:

4 See http://www.g20.utoronto.ca/2013/2013-0906-declaration.html. 
i. Strengthen IBORs in particular by anchoring them to a greater number of transactions, where possible.

ii. Improving the processes and controls around submissions.

iii. Identifying alternative near-risk free rates (RFRs).

iv. Encouraging derivative market participants to transition new contracts to an appropriate RFR, where suitable.

Based on the above, the reform process was divided into task categories. The first one is the establishment of a prudential regulatory system due to which the existing short-term forward-looking IBORs preserve their credibility by developing transparent control, quotation, calculation, publication and application processes which resist to manipulation. As the initiation of this and the development of its main elements did not require the involvement of market participants, this task group seems to be simpler and have less serious consequences. The regulators of the jurisdictions concerned developed the aforementioned regulatory system. At this point, Regulation (EU) 2016/10115, which regulates the issue at EU level should be highlighted, as it regulates not only the setting of benchmarks within the European Union, but also the use of benchmarks set in third countries in the financial system of the EU.

In recent times, it has been revealed that the requirements of transparency and resilience resulted in setting rigorous criteria which led to the cessation of several widely used reference interest rates affecting the majority of the money market and capital market volume or to placing their administration under state guardianship. Such cases include the phasing-out of the most widely used LIBORs in 2022-23, tying EONIA to $€ S T R$ (Euro short-term rate) in an administrative manner, then its phasing-out as of $\mathbf{2 0 2 2}$ or the takeover of the administration of the reference interest rates quoted in currencies of countries which have their own currency in our region by the central banks (Budapest Interbank Offered Rate, BUBOR; Romanian Interbank Offered Rate, ROBOR) or the replacement of such reference interest rates by some kind of calculated artificial reference rate in several places (e.g. in Croatia and Bulgaria). Moreover, this happened despite the fact that IBORs had undergone a serious reform process and the quotation methodologies, which primarily considered the interest rates in the course of real transactions and relied on other market data or expert estimates only later, had been

5 Regulation (EU) 2016/1011 of the European Parliament and of the Council of 8 June 2016 on indices used as benchmarks in financial instruments and financial contracts or to measure the performance of investment funds and amending Directives 2008/48/EC and 2014/17/EU and Regulation (EU) No 596/2014

https:/eur-lex.europa.eu/legal-content/EN/TXT/?uri=CELEX\%3A32016R1011\&qid=1619187638684 
transformed. In the first half of 2020, during the first wave of the new COVID-19 pandemic, the number of underlying transactions dropped to a very low level again. As a result, the view according to which, due to their low resistance to the crisis, IBORs might be replaced by alternative reference interest rates in the nottoo-distant future was gaining ground again.

Another task was the determination of new risk-free interest rates which might replace IBORs if needed. In order to ensure the smoothness and the success of this process, a financial eco-system suitable for managing the given alternative interest rate should be established, with the derivative market, which allows risk transfer, in its centre. In any case, the terminating LIBORs will enforce the transition to alternative backward-looking reference rates calculated on the basis of earlier overnight rates for a term period in the case of currencies, which do not have alternative forward-looking interest rates with appropriate liquidity in their derivative markets (e.g. EURIBOR instead of Euro LIBOR).

In order to explore the applicable risk-free alternative reference rates, develop the replacement methodology and encourage their use, national working groups were set up in the countries of major currencies under the control of central banks and financial supervisory authorities, with the involvement of market participants. These groups worked in close cooperation with the subcommittees representing major global currencies within the FSB OSSG. From a Hungarian perspective, the first committees were set up in countries which relied on LIBOR rates the most: the Swiss SwissNWGs (National Working Group of Swiss Franc Reference Rates) were established in June 2013, prior to the FSB reform programme, the ARRC (Alternative Reference Rates Committee) was set up in the United States in November 2014 and the British UK RFRWG (UK Working Group on Sterling Risk-Free Reference Rates) in March 2015. Similar committees in the European Union and Japan were set up relatively late: the former, the EURO RFRWG (Working group on euro risk-free rates), in February 2018, while the latter, the Yen IRBC (CrossIndustry Committee on Japanese Yen Interest Rate Benchmarks), in August 2018. Although in its roadmap issued in 2014 (FSB, 2014), the FSB calculated with 2016 as the year of risk-free reference rates and the extension of the related transactions in the money and capital markets, the national working groups prepared their relevant recommendations only much later. The recommendations for applicable underlying risk-free interest rates in the case of certain existing short-term reference rates (with maturities longer than one day) were made already in 2017-2018, however, the methodological questions of their application were typically finalised in the autumn and winter of 2020 and at the beginning of 2021. Several other problems which would further delay the use and spread of alternative reference rates arise, however, the termination of LIBOR require to provide a solution to such problems or makes temporary "co-existence" with them inevitable. 
Concurrently with the finalisation of the recommendations on the methodology of risk-free alternative reference rates, the FSB also prepared a global transition roadmap (FSB, 2020) in October 2020, along which it recommended the implementation of the process of the introduction of alternative reference rates to replace LIBOR quotations terminating as of the end of 2021. It can also be interpreted as a kind of task performance checklist. In its recommendation, the FSB recommends financial service providers in the market - inter alia - to reach a level at which they will be able to use reference rates other than LIBOR in new transactions by the end of 2020. By the middle of 2021, processes (developments) allowing the replacement of LIBOR in the case of each contract in a regulated manner, without any legal risks, should be started. The aforementioned processes involve the full preparation of banking operation, including the IT system, for the transition. The roadmap urged the financial supervisory bodies of EU member states and other developed countries concerned to assess the status of the preparatory process at the supervised institutions and compare it with the content of the recommendation. In Hungary, it took place in January 2021.

\subsection{Anomalies related to the termination, replacement of LIBOR (and potentially other IBORs)}

IBORs have been used by developed financial systems of the world for more than 30 years. Banking operations are based on established practices. In spite of the fact that, following the financial crisis of 2008 , the pre-crisis liquidity level has not returned to the market of unsecured interbank "term" - i.e. with maturity over one day and within one year - deposits and loans and, during later milder financial waves, liquidity became limited again and again, due to proper operation of the related derivative markets, in general, it has been possible to set IBORs by calculating implied interest rates to date.

In the case of market participants involved in quotation, transactions, financial theories have approached the considerations behind the development of the shapes of yield curves in different ways. A key element of expectations and liquidity preference hypotheses etc. is grasping the uncertainty according to rate setting happens at the beginning of the period, while the actual cost of funds becomes different from it by the end of the period due to daily exchange rate fluctuations. Based on the above, banks need to hedge their open interest positions continuously in derivative markets.

In their recommendations, national working groups propose that risk-free reference rates should be short-term interest rates (so-called term rates) calculated from overnight average interbank unsecured interest rates or secured market in- 
terest rates related to the given currency. The term rates of appropriate length (e.g. of $1,3,6$ or 12 moths) are usually calculated from overnight interest rates, on the basis of a product series, and are referred to as "compound rate" by means of an umbrella term. However, several problems arise in connection with the practical use of compound rates as IBOR substitute.

IBORs are so-called forward-looking reference rates, i.e. they are already known at the beginning of maturity, while compound rates are backward-looking, i.e. they are disclosed at maturity. It has several consequences. On the one hand, there is some kind of risk transfer towards the client using the interest-bearing banking product, as the reference rate, based on which the client incurs payment obligation, is disclosed at maturity. In the case of the so-called wholesale transactions, this risk transfer may even be considered ethical, but in the case of retail transactions, where the other contracting party is not only unable to manage the risk with appropriate methods, but is not even aware of it, the situation is different. As for retail transactions, this is the reason why this type of interest setting is prohibited pursuant to consumer protection rules in the majority of developed economies. The aforementioned problem can be prevented in several ways: One of the options is to apply the average RFR of a given day or of several days as reference rate in the following interest period (last recent). The other option is the use of the term interest rate calculated from RFR interest rates during the entire interest period for the following interest period (last reset).

There is no practical example for the first case, as it would transfer the volatility of overnight interest rates to banking service relationships, which would result in unreasonably high or low interest rates compared to fair market rates. The use of the latter may be limited by the difference between the reference interest periods of assets and liabilities. The longer the interest period is, the more serious effect this option has. The materials prepared by national working groups reveal that, provided maturities are longer than 3 months, market participants assess this risk to be higher than the advantage of the application of the method. 


\section{Figure 3}

An explanation of the calculation of backward-looking methodologies
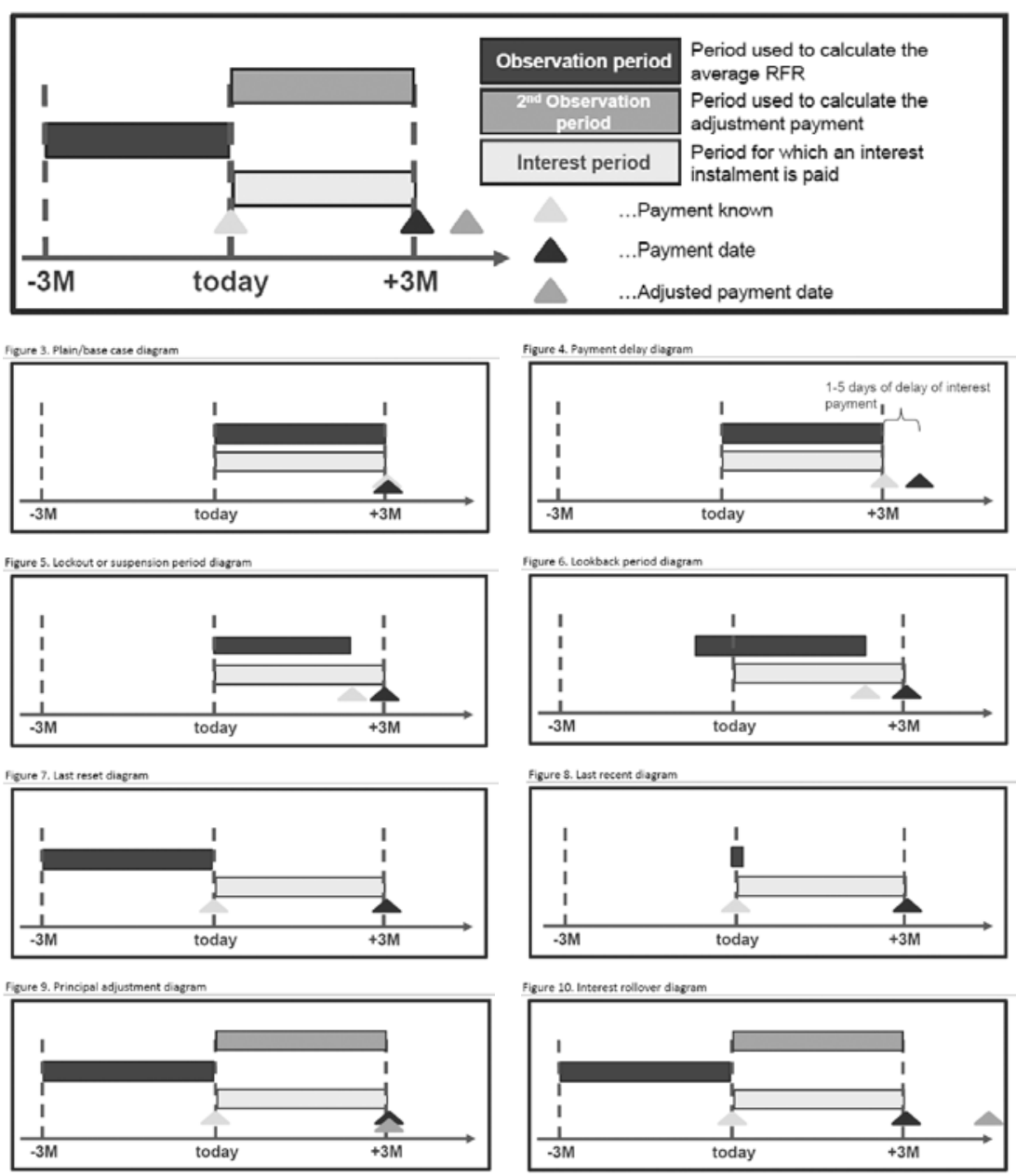

Source: ECB (2020)

Considering backward-looking interest rates, another problem is the lack of future uncertainty in the course of quotation, which financial theory tried to explain by means of the hypotheses described above. However, future uncertainty is an integral part of forward-looking interest rates. Therefore, if a forward-looking IBOR is replaced by a backward-looking RFR to solve the problem above, automatic value transfer occurs, as the latter lacks the "term premium" for covering uncertainty. Currently, there is no exact methodology for determining this 
in real market environment. Long consultation was held between the individual national working groups and the developers of international market standards to find a solution that treats the issue of value transfer minimization in a fair manner. Eventually, the statistical approach (the median of the difference between the terminating and the fallback rates over the past 5 years) recommended for OTC derivatives by the ISDA has become generally accepted.

The phasing-out of a reference rate for any reason is the result of a relatively long process. The administrators are expected to announce their intention years earlier, so that market participants can adapt appropriately. The IBA, as administrator, already announced in 2017 (ICE, 2017) that LIBOR is expected to be phased out from most currencies and all of their maturities in early 2022, from major USD maturities in the middle of 2023. The British financial supervisory authority also pointed out that it did not intend to take any steps to maintain quotations in a later period. Despite the fact that this deadline might have seem long enough, at the time of the announcement, there were some long-term, mainly bilateral loan transactions and capital market instruments whose maturities were due in the period after the phasing-out and the amount of payment obligations under these contracts was benchmarked to the interest rate to be phased out. If the contracts and instruments concerned do not contain any fallback language/provision on termination or the fallback language/provision does not specify a replacement rate clearly or the setting/quotation of the replacement rate is not independent of the bank (i.e. the bank's influence cannot be completely excluded), the parties' mutual consent is required for setting the fallback rate and specifying the methodology that ensures fair use (e.g. spread). The fulfilment of the requirement above is operationally unfeasible due to the character of a given facility (e.g. securities) and/or the large number of the clients concerned or would need disproportionate effort or resources. In the case of the above-mentioned so-called "tough legacy" contracts, state actors should intervene by means of legislative instruments. At the same time, the reasonableness and degree of this intervention requires thorough consideration, as it might violate constitutional rights by intervening into private contractual relationships, infringing the constitutional property rights of citizens. Another solution for handling a wide range of transactions is the use of market standards. However, this option works only between expert partners. Such a solution for the management of OTC derivatives presented earlier is joining the ISDA protocols, which, concerning the replacement of the terminating LIBOR (ISDA, 2020), entered into force at the end of January 2021.

Based on the above, it is clear that, provided the solution using legislative or market standards does not work, the institutions have to amend the contracts with their clients and partners, having taken into account the mutual consent of the parties. Possible solutions may differ by jurisdiction or client type. It can certainly be stated 
that, in addition to the avoidance of legal risks, it is also very important that the character of fallback rates entering the contracts and the large number of their application methods should not result in excessive complexity in banking operations, as this would exponentially increase operational risks and operating costs.

Earlier, our study mentioned the difficulties caused by and the considerations made necessary by the use of risk-free interest rates as alternative reference rates, e.g. the use of a backward-looking rate instead of a forward-looking rate, and the value transfer owing to different content in asset-liability management. It is important to stress that effective and capital-friendly financial mediation is based on closing certain open market positions. In the case of interest rate positions, it also means that bank treasuries use the hedging methodology adjusted to the interest rates and methodology applied in the course of lending. However, in order to use this methodology, the market of the required interest rate derivatives has to be liquid. If the number of interest rates and application methodologies chosen ${ }^{6}$ by an institution is too high, during continuous operation, the institution may encounter the following problem: the transaction volume on the asset side will not be enough to satisfy the minimum size of hedging (ticket size) within the given period, therefore the portfolio concerned will be appropriately hedgeable only after longer accumulation, which might increase basis risk. In addition, mainly in the period after the termination of LIBOR, another problem may arise when hedging positions: in the case of cross-currency interest rate swap (CIRS or CCIRS) transactions, different types of interest rates should be considered on the two sides of the transaction. However, in the absence of market practice, there is no solution to their comparison. The National Working Group of Swiss Franc Reference Rates (SwissNWG) suggested the following solution ${ }^{7}$ to the problem: in different currencies, fixed interest rates should be set by means of simple IRSs. The replacement of such rates leads to a similar result, however, this method requires 3 transactions and has higher costs. As for cross-currency interest rate swap transactions, a special assessment situation may be caused by the fact that some recommended RFRs are based on unsecured market quotations (e.g. €STR, Sterling Overnight Index Average, SONIA, Tokyo Overnight Average Rate, TONA), while other are based on secured (repo) market quotations (e.g. Secured Overnight Financing Rate, SOFR, Swiss Average Rate Overnight, SARON).

In conclusion, it is obvious why the transition period originally planned by the FSB has delayed and why the termination of LIBOR will enforce the wide-spread

6 See The part of Diagram 3 that indicates that, in principle, how many methods can be developed in the case of any RFR in a given currency.

7 See https://www.isda.org/protocol/isda-2020-ibor-fallbacks-protocol/. 
use of risk-free interest rates as alternative interest rates. In the complexity of transition, the dilemma of "Which comes first, the chicken or the egg?" plays an important role. In interest rate derivative and relevant markets, banks are participants, which provide considerable liquidity. Concerning alternative interest rates, they do not enter into a large number of hedges, which constitute considerable volume in the markets, until they do not have plenty of open positions, e.g. balance sheet exposure, because of significant basis risk. On the other hand, despite pilot solutions, banks did not intend to widely modify the complete banking operation related to interest-bearing banking services (methodology of transaction interest rate quotation, provisions on client contracts, customer service, customer and information methods, the related product and IT system development, etc.) until derivatives with appropriate liquidity needed for the closing of the positions are not available.

\subsection{Dilemmas in the European Union and solution methods}

As part of the reform process, in September 2013, the European Commission submitted its draft regulation dealing with the issue within the territory of the EU. Regulation (EU) 2016/1011 was published in the EU's official journal at the end of June 2016, ensuring a preparatory period of one and a half years for those concerned. It came into force as of the start of 2018.

The regulation primarily focused on provisions on the restoration of confidence in existing benchmarks, while it provides for the tasks related to the termination of a benchmark only in two places: on the one hand, it specifies the concerning responsibilities of the administrators of benchmarks and the rights of the competent authorities to extend interest rate quotation to a short period. On the other hand, which is more important regarding our topic, it also prescribed how the supervised institutions of the EU have to prepare for the termination of a benchmark.

The principle-based regulation prepared for the latter was rather rough-andready $^{8}$, which is not surprising based on the status of works in progress in connec-

8 Art. 28 Section 2. Supervised entities other than an administrator as referred to in paragraph 1 that use a benchmark shall produce and maintain robust written plans setting out the actions that they would take in the event that a benchmark materially changes or ceases to be provided. Where feasible and appropriate, such plans shall nominate one or several alternative benchmarks that could be referenced to substitute the benchmarks no longer provided, indicating why such benchmarks would be suitable alternatives. The supervised entities shall, upon request, provide the relevant competent authority with those plans and any updates and shall reflect them in the contractual relationship with clients. 
tion with fallback rates at the time of the finalisation of the regulation (in the first half of 2016). The most important element of the regulation is that institutions shall have robust written plans on the termination of a benchmark and it shall also be reflected in their contractual relationships.

The ESMA further specifies the interpretation of these rules in the form of questions and answers (Q\&A) $)^{9}$. The ESMA also indicates that the plans have to be ready at the time of the BMR's entry into force, which involves the obligation related to contractual relationships, as well. The ESMA describes what it considers to be appropriately robust and what fulfils the criteria for inclusion in business relationships. Moreover, it stresses that the aforementioned criteria shall be modified (revised) if necessary.

In principle, in the light of the above, we might suppose that the appropriate fallback language/provisions on the termination and replacement of reference rates have been included in all contracts (including general terms and conditions) concluded since 1 January 2018, and, in the case of transactions concluded prior to the effective date of the BMR, the subsequent incorporation of fallback language/provisions in such contractual facilities has started. In practice, in spite of the legal provision, due to the character of the problems explored in the previous chapters and the slow process of making proposals on the solution of certain issues, it has not always been the case. In terms of the management of legal/litigation risks, the solutions have not necessarily been satisfactory.

The following question arose relatively early: If the drafted regulations do not manage litigation risks appropriately in all aspects, legislative intervention might be necessary in some cases (see: certain "tough legacy" contracts). A special interim solution to this problem was proposed by the British: the use of the so-called synthetic LIBOR (Synthetic LIBOR or Transition LIBOR). At the same time, the EU, which has been left by the UK, is trying to tackle the problem by setting a compulsory replacement rate.

The idea of synthetic LIBOR appeared in the United Kingdom in early 2018. At the time, the UK was still an EU member state, but Brexit had already started. The idea of synthetic LIBOR was quickly embraced by the British Financial Conduct Authority (FCA). The main point is that the FCA shall oblige the parties concerned to extend GBP LIBOR, JPY LIBOR and USD LIBOR quotations (the latter two for a limited period) pursuant to a British law and publish synthetic LIBORs in the same way and place as certain terminating LIBORs, thus ensuring that synthetic LIBORs shall not qualify as new reference rates in terms of contract law.

9 See in the document No. ESMA70-145-114: https://www.esma.europa.eu/system/files_force/ library/esma70-145-114_qas_on_bmr.pdf?download=1. 
However, the use of synthetic LIBORs would not be allowed in the case of new contracts. Currently, the British Parliament is discussing the law, based on which the synthetic LIBOR can be set.

The situation that evolved during the first wave of the pandemic showed the vulnerability of IBORs to financial crises again, which, along with the approaching date of the termination of LIBOR encouraged European legislative bodies to take action. In July 2020, the European Commission presented its proposal to amend the BMR to deal with those cases of the benchmarks' termination which the market is unable to cope with on its own, without considerable financial stability risks. The proposal was approved by co-legislators relatively fast and was published under No. (EU) 2021/168 in the official journal of the EU on 12 February 2021.

The regulatory objective itself should be definitely welcomed by the banking sector, as it solves the aforementioned problems and dilemmas by legal means independent of the institutions. On the other hand, the applied solution and its details leave several questions of interpretation unanswered. Presumably, this is the reason why the European Commission does not use this instrument widely.

One of these questions is whether this instrument can be reasonably used from a constitutional viewpoint, i.e. whether the legislator has the right to intervene into civil contractual relationships without infringing any constitutional rights. If the legislator has the right to use this instrument, what are the conditions and limits of its use? A solution that is unassailable from all aspects and minimises legal/ litigation risks can be reached only with the support of all powers. Otherwise, ultimately, in specific cases, the courts may challenge it with their decisions made to the detriment of banks which fulfil their legal obligations. The problem is not unknown in Hungarian banking history. A similar problem escalated in connection with foreign currency loans in 2012. In the end, at the request of the government, the Constitutional Court settled it with its decision of March 2014. ${ }^{10}$ Although the given amendment to the BMR maintains the priority of the will of the contracting parties when prescribing the conditions of the replacement of the reference rate, the constitutional test of the solution by EU courts has not happened yet.

In addition, the personal scope of the EU BMR exceeding its own jurisdiction carries a legal risk. ${ }^{11}$ It is fairly doubtful whether in the case of a contract settled in London and concluded between EU institutions under the British law, the alternative reference rate set by the European Commission would remain applicable instead of the British reference rate (e.g. a synthetic USD LIBOR) (Financier

\footnotetext{
10 See http://public.mkab.hu/dev/dontesek.nsf/o/EE3A84E45401B26EC1257C320060ooE6?OpenD ocument.

11 See Point b) of Article 23a. of the BMR.
} 
Worldwide, 2020). Of course, this problem does not have any significant relevance regarding the Hungarian banking sector.

Another question is when a contract can be considered to an agreement that does not include any fallback provision for the reference rate in accordance with the definition of BMR amendment, or when is the provision regarded as inappropriate or appropriate. In banking practice, it is an accepted contractual solution both in Hungary and abroad that the contracts tied to reference rates specify the reference rate or other benchmark that shall be used if the reference rate ceases to exist. Contractual documentations tend to define this situation as temporary termination due to temporary market disturbance, however, this feature is not specified on many occasions. In many cases, these LIBOR fallback mechanisms have remained in practice since the BMR's coming into force. The question arises whether, in terms of the BMR or contract law in general, such mechanisms can be considered to be appropriate fallback provisions in the event of the final termination of LIBOR or any other reference rate, or whether such cases should be considered to be inappropriate fallback provisions, taking into account that they belong to the category defined in Point a) of Section (4) of Article 23 b. $^{1213}$

It is also interesting whether a fallback provision that does not clearly specify one fallback rate and the applicable methodology can be appropriate or not. In each case where potentially more options are provided for replacement, legal/litigation risk can only be avoided if the replacement is based on the mutual consent of the parties. However, in this case, the fallback provision becomes inappropriate exactly for the aforementioned reasons, as in this situation as if no such clause had existed. As we mentioned earlier, national working groups and the ISDA finalised their recommendations on the application methodology of fallback reference rates at the end of 2020 and in early 2021. Consequently, earlier, the EU's banks might not have been in a situation to solve the replacement of LIBOR rates in their contractual relationships, or they should have applied a complicated socalled "waterfall" mechanism that would have brought unmanageable complexity into their banking operations.

It should also be examined whether a fallback rate and a methodology prescribed by the European Commission could be applied selectively, only for certain products or customer groups. In other words, irrespective of the fact that the regulatory solution aims to enable the management of "tough legacy" contracts, should the institutions use this fallback rate in other cases, even if the application of

12 See Wyman-Polk (2018).

13 ...fallback language/provision is considered to be inappropriate if:

a) it fails to provide for the final replacement of the terminating benchmark; 
another type of reference rate was reasonable in their banking operations? Of course, the contractual will of the parties is given priority, therefore, as a last resort, a contract amendment shall be concluded in such a case. However, where the conclusion of an amendment is impossible, because it would be too resourceintensive or there is a lack of mutual will, based on the interpretation of the BMR amendment, it is questionable whether a reference rate or a methodology different from those prescribed by the Commission can be used in the case of any product, even if the Commission examines the replacement of CHF LIBOR by a law expressly for certain product scopes (retail loans and SME loans). ${ }^{14}$

Timeliness is another problem in connection with cases specified in Point c) of Section (4) of Article 23b of the BMR in which the procedures define in Section (5) and (6) should be implemented. In such cases, due to the wide-spread use of LIBORs, presumably the colleges of the authorities of the member states concerned should conduct the procedure. However, pursuant to the BMR amendment, Member States shall appoint the competent national authorities only by the middle of August, therefore it is still unknown whether the procedures can be conducted in a manner that leaves enough time for the transformation of banking operations and IT systems.

In March 2021, the European Commission started a consultation of nearly 2 months (European Commission, 2021), proposing the replacement of CHF LIBOR rates by $3 \mathrm{M}$ SARON ( 3 monthly compound SARON) with a spread according to the ISDA methodology. Furthermore, the proposal is aimed at retail loans and SME loans only, and the reference rate - mainly in compliance with consumer protection regulations - shall be known at the start of the interest period, the Commission recommends the use of the last reset method for the calculation of the given periodic interest rates. At the same time, the consultation material leaves several questions unanswered.

In order to justify the Commission's intervention related to the CHF LIBOR, the consultation material refers to the prevalence of CHF LIBOR in retail lending in several member states and the financial stability risk arising from the phasing-out of LIBOR. It also explains that the content of the proposal was requested by the interest representatives of banks as well as by the regulatory/supervisory authorities of the member states concerned. The question arises whether the Commission would be willing to intervene in response to other requests, in the case of LIBORs in other currencies? According to market information, with the support of large EU member states, a demand for the Commission's intervention in the case of sterling LIBORs is being formed. In this respect, the development of a

14 See EC (2021). 
synthetic sterling LIBOR will be an important circumstance, as well as its legal environment and applicability by the supervised institutions under the jurisdiction of the EU.

At the moment, it is also uncertain regarding the consultation material whether CHF LIBORs would be replaced by ${ }_{3} \mathrm{M}$ SARON in the case of all maturities, or the current proposal should be complemented by SARONs with other maturities (at least $1 \mathrm{M}, 6 \mathrm{M} 12 \mathrm{M}$ ), comparing the maturities of the interest rates to be replaced and those of alternative rates. The drawback of the first solution is that, in the case of CHF LIBOR with other maturities, the interest period has to be changed in client contracts. Concerning retail loans, it is prescribed by Act CLXII of 2009 on Consumer Credit (Fhtv.) in Hungary, as the interest period shall comply with the maturity of the reference rate. In the course of the conversion of foreign currency retail loans into HUF, the Hungarian banks concerned experienced the incurred operating burden and that, irrespective of legal references, it could result in the loss of customers' confidence in banks. As mentioned earlier, the disadvantage of the latter solution is that the use of the last reset method is problematic for interest periods longer than 3 months.

Another question based on the consultation is why the Commission intends to make the replacement compulsory only in the case of retail and SME loans. As described earlier, prescribing selective application could be doubtful in accordance with the current provisions of the amended BMR.

\subsection{Further implementation tasks}

If we consider the FSB's roadmap for the adaptation of institutions to the phasingout of LIBOR well-founded, all the questions raised above should be addressed reassuringly by the summer of 2021 and derivative markets with appropriate liquidity should operate even in the case of risk-free alternative interest rates. By the date of LIBOR's phasing-out, the availability of such conditions seems to be an unattainable task in the shadow of the consequences of the pandemic, due to increased expectations towards banks because of the economic recovery, the entry into force and application of new European regulations on capital requirement ${ }^{15}$, the implementation of sustainability issues and staying competitive in digitalisa-

15 Here, it is worth mentioning that the BCBS (Basel Committee on Banking Supervision) published a relatively short Q\&A on the role of benchmarks. It is a systematic assessment of the benchmarks' effect on interest-bearing assets in banking-books, the effect of the FRTB's (Fundamental Review of the Trading Book) implementation, the concurrent processes of LIBOR's phasing-out and the spread of risk-free reference rates, the role of transition to the new operational risk methodology and certain IFRS (International Financial Reporting Standards) methodologies, etc. 
tion. It is important to maintain the supportive attitude of authorities even after the phasing-out of LIBOR and to cope with temporary uncertainty in risk management with reasonable prudential measures facilitating adaptation.

In Hungary, currency portfolios affected by the phasing-out of LIBOR do not cause any serious risk at sectoral level. On the one hand, they are not evenly distributed at institutional level, on the other hand, irrespective of their multiplicity, institutions have to make the same effort to adjust banking operations to their management as if they appeared in large volume.

In addition to monitoring the adaptation process of banks, the National Bank of Hungary has other duties related to fallback rates, as well. In accordance with the regulation on fair banking, the modification of interest rate spreads in the case of floating rates is tied to so-call interest rate spread modification indices. Indices related to foreign currency loans use LIBORs or other market instruments which rely on the application of LIBOR. In order to ensure legal certainty, presumably, the calculation methodology of these indices should be revised, and their already published values should be recalculated retroactively. In addition, the central bank is responsible for the operation of BUBOR quotations, and it is not planning to delegate this duty to market participants. However, the fallback provisions, which fully comply with the provisions of the BMR, shall also regulate the potential replacement of HUF reference rates. In order to achieve this, appropriate reference interest rates and fallback methodology should be developed. The model for this process is given, but a Hungarian reference rate working group should be set up with the support of the central bank and the involvement of market experts.

\section{SUMMARY AND CONCLUSIONS}

First, the paper intended to outline the necessity of the reference rate, its bestknown type, LIBOR (London Interbank Offered Rate) and the attempts to manipulate it. If the attempts to reform the index is to be understood, it is especially important to become familiar with these financial market terms. The study introduced the types of possible future reference yields in financial markets and the related regulatory issues, pointed at further regulatory aspects which have to be paid adequate attention in the future, as well. The overview included not only the European, typically EU regulation, but it also provided international outlook to throw different light on European regulatory anomalies.

In the light of this overview, it is important to stress that in Hungary, currency portfolios affected by the phasing-out of LIBOR do not cause any serious risk at sectoral level, but risks are not evenly distributed at institutional level. It is still 
an important question whether banking operation can make an effort to adapt even to a possibly large volume of risks. Furthermore, as the indicators related to foreign currency loans are based on LIBORs, in order to ensure legal certainty, it is worth revising the calculation methodology of these indicators and considering the retroactive recalculation of the values published earlier. Another important recommendation is, in connection with BUBOR quotations operated by the central bank, extension for replacement of HUF reference rates and the establishment of a reference rate working group with the involvement of market experts.

\section{REFERENCES}

Accenture (2019): EONIA and Euribor reform: ESTER is here to see you. https://www.accenture. com/nl-en/blogs/insights/eonia-and-euribor-reform-ester-is-here-to-see-you you.

CFR (2016): Council on Foreign Relations (CFR) (2016): Understanding the Libor Scandal. Council on Foreign Relations, https://www.cfr.org/backgrounder/understanding-libor-scandal.

Duffie, D. - Stein, J. C. (2015): Reforming LIBOR and Other Financial Market Benchmarks. Journal of Economic Perspective, 29(2), 191-212.

EC (2021): Targeted consultation on the designation of a statutory replacement rate for CHF LIBOR. Consultation document, European Comission, https:/lec.europa.eu/info/sites/default/files/ business_economy_euro/banking_and_finance/documents/2021-chf-libor-rate-consultationdocument_en.pdf.

ECB (2017): Update on reference rate reforms in the euro area. Financial Stability Review, November, https://www.ecb.europa.eu/pub/financial-stability/fsr/focus/2017/pdf/ecb 7a761e33fb.fsrbox201711_02.pdf.

ECB (2018): Euro short-term rate (€STR). https://www.ecb.europa.eu/stats/financial_markets_and_ interest_rates/euro_short-term_rate/html/index.en.html.

ECB (2020a): Public consultation by the working group on euro risk-free rates: on $€ S T R$-based EURIBOR fallback rates. https://www.ecb.europa.eu/pub/pdf/other/ecb.pubcon_ESTRbasedEURI BORfallbackrates.202011 d7b62f129e.en.pdf.

ECB (2020b): Report on preparations for benchmark rate reforms. https://www.bankingsupervision. europa.eu/ecb/pub/pdf/ssm.reportpreparationsbenchmarkratereforms202007 bd86332836. en.pdf.

EMMI (2018): EURIBOR Reform. https://www.emmi-benchmarks.eu/euribor-org/euribor-reform. html.

EMMI (2019): Benchmark Determination Methodology for EURIBOR. https://www.emmi-benchmarks.eu/assets/files/Doo16A-2019\%2oBenchmark\%20Determination\%2oMethodology\%20 for\%2oEURIBOR.pdf.

EMMI (2021a): About EURIBOR. https://www.emmi-benchmarks.eu/euribor-org/about-euribor. html.

EMMI (2021b): EURIBOR Rates. https://www.emmi-benchmarks.eu/euribor-org/euribor-rates. html.F

Erhart, Sz. - Ligeti, I. - Molnár, Z. (2013): Reasons for the LIBOR review and its effects on international interbank reference rate quotations. MNB Bulletin, January. https://www.mnb.hu/ letoltes/erhart-ligeti-molnar.pdf. 
ESMA - EBA (2013): ESMA-EBA Principles for Benchmark-Setting Processes in the EU https://www. esma.europa.eu/system/files_force/library/2015/11/2013-659_esma-eba_principles_for_benchmark-setting_processes_in_the_eu.pdf?download $=1$.

EMMI (2019): EURIBOR Governance Code of Conduct. https://www.emmi-benchmarks.eu/assets/ files/Doo18C-2019-EMMI\%2oGovernance\%20Code\%20of\%2oConduct.pdf.

Financier Worldwide (2020): Transitioning 'tough legacy' LIBOR contracts - different strokes for different folks? https://www.financierworldwide.com/transitioning-tough-legacy-libor-contracts-different-strokes-for-different-folks\#.YImas7UzaMp.

FLIszÁr, V. (2015): Csökkenthetö-e a referencia-kamatlábak manipulálásának valószínűsége? [Can the probability of manipulation of reference interest rates be reduced?]. Közgazdasági Szemle, 62(11), 1158-1171.

FSB (2020): Global Transition Roadmap for LIBOR. https://www.fsb.org/wp-content/uploads/ P161020-1.pdf.

Global Rates (2021): LIBOR, information about the London InterBank Offered Rate. https://www. global-rates.com/en/interest-rates/libor/libor-information.aspx.

Guardian (2017): Libor scandal: the bankers who fixed the world's most important number. https:// www.theguardian.com/business/2017/jan/18/libor-scandal-the-bankers-who-fixed-the-worldsmost-important-number.

ICAEW (2021): Interbank rates. (https://www.icaew.com/library/subject-gateways/financial-markets/knowledge-guide-to-base-rates/interbank-rates.

ICE (2017): IBA publishes feedback statement for consultation on its intention to cease publication of LIBOR settings. https://www.theice.com/iba

ICE (2021): LIBOR. https://www.theice.com/iba/libor.

International Swaps and Derivatives Association (ISDA): ISDA 2020 IBOR Fallbacks Protocol. http://assets.isda.org/media/3062e7b4/o8268161-pdf/.

IOSCO (2013): Principles for Financial Benchmarks. https://www.iosco.org/library/pubdocs/pdf/ IOSCOPD 415.pdf.

KLINGer, S. - Syrstad O. (2021): Life after LIBOR. Journal of Financial Economics,14O(2), https:// doi.org/10.1016/j.jfineco.2021.04.017.

Kovács, L. - PÁsztor, Sz. (2018): A jelzálogpiac helyzete és kihívásai [The Situation and Challenges of the Mortgage Market]. Közgazdasági Szemle, 65(12), 1225-1256.

KPMG (2019): A referenciakamat rendszer reformja [The Reform of the Reference Rate System]. Financial Risk and Regulation, Newsletter, January 2019. https://assets.kpmg/content/dam/kpmg/ hu/pdf/rfr_hirlevel_4.pdf.

PÁszToR, Sz. (2018): Future of Commercial Banks - Survival or Failure? Izvestiya, Mezhdunarodnyy teoreticheskiy i nauchno-prakticheskiy zhurnal, 23(4), 71-88.

PWC (2020): Understanding ISDA's IBOR Fallback Protocol: What's next for financial institutions? https://www.pwc.com/us/en/industries/financial-services/regulatory-services/libor-referencerate-reform/isda-fallback-protocol.html.

SCHRImPf, A. - Suschкo, V. (2019): Beyond LIBOR: a primer on the new reference rates. BIS Quarterly Review, March 2019, 29-52. https://www.bis.org/publ/qtrpdf/r_qt1903e.pdf.

SCHRIMPf, A. (2019): Beyond LIBOR: a primer on the new reference rates. Presentation, EMMI, Brüsszel, 2019. június 27. https://www.bis.org/publ/qtrpdf/r_qt1903e.pdf.

Stenfors, A. - Lindo, D. (2018): Libor 1986-2021: the making and unmaking of the world's most important price'. Distinktion: Journal of Social Theory, 19:2, 170-192. DOI: 10.1080/1600910X.2018.1430599. https://www.researchgate.net/publication/323122200_Libor_1986-2021_the_making_and_unmaking_of_the_world's_most_important_price'. 
Strotкамp, M. (2018): The LIBOR Scandal: A Comparison of Banks Involved Concerning the Impact of Disclosure and the Imposition of Fines on Stock Prices. https://www.wiwi-frankfurt.de/ wp-content/uploads/2019/03/dka-03-005.pdf.

UBS (2021): Annual Report. https://www.ubs.com/global/en/investor-relations/financial-information/annual-reporting/ar-archive.html.

UK Finance (2019): Discontinuation of Libor - UK Finance guide for business customers. https:// www.ukfinance.org.uk/system/files/LIBOR-Guide-for-Business-Customers-FINAL_1.pdf.

VAInikainen, J. (2018): Market Pulse EUR: Goodbye EONIA swaps, welcome ESTER. Nordea, 26 Sept. https://corporate.nordea.com/article/46133/market-pulse-eur-goodbye-eonia-swaps-welcome-ester.

Wyman, O. - Polk, D. (2018): LIBOR Fallbacks in Focus a Lesson in Uninteded Consequences. https://www.oliverwyman.com/content/dam/oliverwyman/v2/publications/2018/may/Oliver\%20 Wyman\%20-\%2oLIBOR\%2oFallbacks\%20in\%2oFocus.PDF

Youle, T. (2014): Essays on Libor Manipulation. PhD Dissertation, University of Minnesota, July 2014. https://conservancy.umn.edu/bitstream/handle/11299/165691/Youle_umn_013oE_15225. pdf? sequence $=1 \&$ is Allowed $=y$.

Websites of the reference rate working groups of the major global currencies

ARRC (Alternative Reference Rates Committee, USA): https:/www.newyorkfed.org/arrc

EURO RFRWG (Working group on euro risk-free rates): https:/www.ecb.europa.eu/paym/interest_rate_benchmarks/WG_euro_risk-free_rates/html/index.en.html.

SwissNWG (National Working Group of Swiss Franc Reference Rates): https://www.snb.ch/en/ifor/ finmkt/fnmkt_benchm/id/finmkt_reformrates.

UK RFRWG (UK Working Group on Sterling Risk-Free Reference Rates): https://www.bankofengland.co.uk/markets/transition-to-sterling-risk-free-rates-from-libor/working-group-on-sterling-risk-free-reference-rates.

Yen IRBC (Cross-Industry Committee on Japanese Yen Interest Rate Benchmarks):https://www.boj. or.jp/en/paym/market/jpy_cmte/index.htm/. 